\title{
Research of Automatic Adjusting Underwater Sludge Discharge Regulator
}

\author{
Zhao Liu, a, Jianglin Cheng ${ }^{2, b}$ and Yutian Zhu ${ }^{3, c}$ \\ ${ }^{1,2,3}$ School of Mechanical Engineering, Tongji University, 4800 Caoan Road, Jiading District, \\ Shanghai, China \\ aliuzhao@tongji.edu.cn, ${ }^{b}$ chengjl@163.com, yutianzhu@tongji.edu.cn
}

Keywords: rainwater storage tank, sludge discharge regulator, self-maintenance, self-regulation Abstract. In order to solve the problem that no suitable technologies are available for the sludge removing of rainwater storage tank, a novel set of sludge discharge regulator has been designed, its principle is explained, its structures and components are introduced, the working conditions are analyzed. The analysis results show that the regulator has strong adaptability to various circumstances. The regulator can automatically adjust its port size and relieve the blockage under certain congestion conditions.

\section{Introduction}

In rainwater runoff, sands and leaves were carried from the ground into the rainwater collecting tank, furthermore they will deposit on the bottom of storage tank, if it is not promptly cleaned up, the sediment will accumulate more and more, and the sludge will pollutes the water, the storage tank cannot exert their effects. In engineering applications, many ways are used to flush the silt ${ }^{[1 \sim 7]}$, but the current dredging method have a commom problem, they cannot remove the sludge in the water. In order to improve the water quality, extend the storage time of rainwater in the collecting tank, a sludge discharge regulator is designed. It can provide solutions for dredging sludge in rainwater collecting tanks.

\section{The functional requirements of the sludge discharge regulator}

The discharge regulator is used in the rainwater storage tank. It can adjust the opening degree of the port according to the sludge density and flow state, and it can automatically remove the block and clean itself without extra control and energy.

The principle of the underwater sludge discharge system is shown in figure 1,

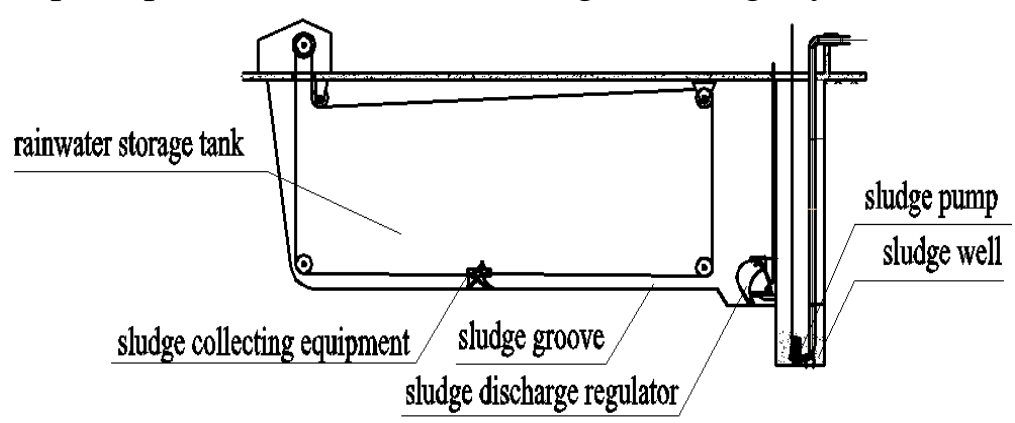

Fig. 1 The principle of the underwater silduge discharge system

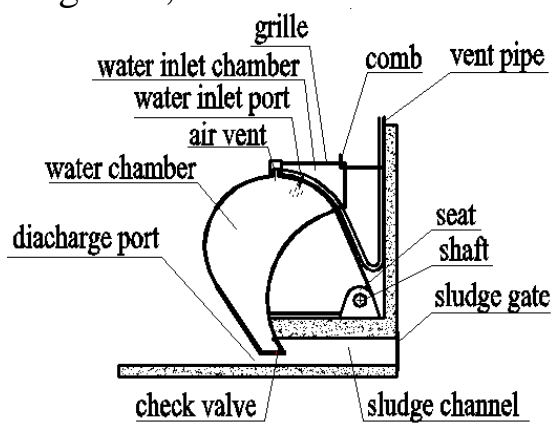

Fig. 2 The structure and principle of the slduge discharge regulator

The regulator is installed in the bottom of the sludge groove of the rainwater storage tank. By using the sludge collecting equipment, the sludge is collected to the port of the sludge discharge regulator, and the sludge is discharged into the sludge well, and then, the sludge pump pumps the sludge out of the well, and the relatively clean rainwater is retained in the tank.

\section{The structure and principle of the sludge discharge regulator}

The structure and principle of the regulator are shown in Figure 2, the regulator consists of water chamber, air vent, water inlet port, water inlet chamber, grille, comb, vent pipe, seat, shaft, sludge gate, sludge channel, check valve and discharge port. The seat is mounted on the foundation of the rainwater 
storage tank. The water chamber is jointed to the seat. The water chamber can rotate around the shaft freely. The air vent and the water inlet port are on the top of the water chamber. The grille is welded around the water inlet port. The comb is mounted on the foundation of the regulator body. The water inlet chamber is formed between water chamber and the grilles, and it can keep the inlet water clean.

In rainwater storage tank, the clean water flows into the water chamber through the inlet port. The air vent interlinks to the atmosphere through the vent pipe to balance the pressure between the water chamber and the atmosphere. The check valve is mounted on the bottom of the water chamber. It adjusts the water pressure which is in the water chamber and the sludge channel. When the discharge port is blocked, the flow in the sludge channel will reduce or no liquid flow. The pressure in the sludge channel will be lower than the pressure in the water chamber. The check valve will open and then the water will flow out of the water chamber. With the water level in the water chamber drops, the weight of the regulator will reduce. When the total weight of the regulator and the water is less than the buoyancy, the regulator will rise, the discharge port will be enlarged, and the blocked sludge will be released. In the meantime, the clean water flows out of the water chamber, dilute the sludge in the sludge channel. Therefore the flow ability of the sludge is enhanced. When the blockage is dredged, the flow through the sludge channel will return to normal state, the pressure rises up and the check valve opening will reduce. The water in the tank will rise up, the weight of the water will rise up, then the regulator drops down to the normal position. While the regulator rotates, the grille and the comb will move relatively. The dross which is filtered on the grille will be removed automatically to make sure that the water in the water chamber is cleaning.

\section{The opening and closing condition of the sludge discharge regulator}

The gravity of water in the water chamber is the direct factor to make the regulator up or down. When the water weight and the regulator is less than the buoyancy of the regoulator, it will rotate upwards, then the discharge port opens. When the water weight and the regulator is heavier than the buoyancy of the regulator, it will rotate downwards, and then the discharge port closes small. The relation between the volume of the water chamber, the relation between the gravity of the regulator and its structural characteristics is

$$
V_{w} L_{w 0} \cos \varphi_{w}=\frac{2 \beta_{1} T_{r}}{\rho_{w} g}
$$

Where, $V_{w}$ is the water volume in the tank, $L_{w o}$ is the distance from the water gravity center to the center of the shaft, $\varphi_{w}$ is the angle between the line of which from water gravity center to the shaft and the horizontal line, $\rho_{w}$ is the water density, $\mathrm{g}$ is the gravity acceleration. $T_{r}$ is the resistance momen, $\beta_{l}$ is the reliable coefficient. Formula (1) shows that the resistance momen $T_{r}$ is the basics of design.

In this paper, $T_{r}=600 \mathrm{Nm}, \rho_{w}=1000 \mathrm{~kg} / \mathrm{m} 3, \mathrm{~g}=9.8 \mathrm{~m} / \mathrm{s} 2, \beta_{l}=1.2, \varphi_{w}=45^{\circ}, L_{w o}=0.3 \mathrm{~m}, V_{w}=0.6927 \mathrm{~m}^{3}$. The regulator material properties and its gravity position can be calculated by the following formula

$$
V_{x} L_{x \mathrm{o}} \cos \varphi_{x}=\frac{\beta_{2} T_{r}}{\left(\rho_{x}-\rho_{w}\right) g}
$$

Where, $V_{x}$ is the volume of the water chamber material, $L_{x o}$ is the distance from the gravity center of the water chamber to the center of the shaft, $\varphi_{x}$ is the angle between the line of which from the gravity center of the water chamber material to the center of the shaft and the horizontal line, $\rho_{x}$ is the density of the water chamber material, $\beta_{2}$ is the reliable coefficient.

In application $T_{r}=300 \sim 1000 \mathrm{Nm}, \rho_{x}=8930 \mathrm{~kg} / \mathrm{m} 3, \rho_{w}=1000 \mathrm{~kg} / \mathrm{m} 3, \mathrm{~g}=9.8 \mathrm{~m} / \mathrm{s} 2, \beta_{2}=1.2, \varphi_{x}=45^{\circ}$, $L_{x o}=0.3 \sim 2 \mathrm{~m}$, then we obtain the result of relation of the material volume and the moment arm. Figure 3 
shows the curve of the relation of the material volume and the moment arm at different resistance moment $T_{r}$.

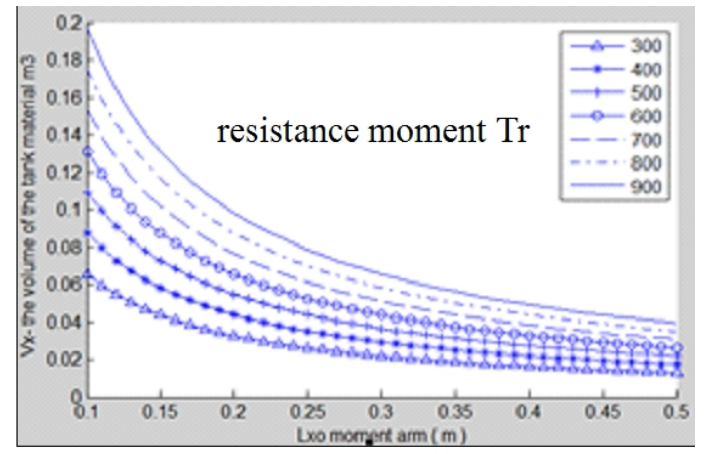

Fig. 3 Curve of the relation of the materoal volume and the moment arm

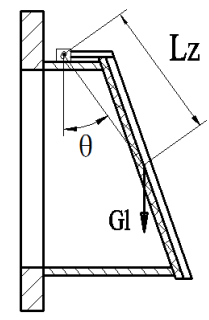

Fig. 4 The analysis of the check valve

\section{The opening and closing condition of the check valve}

The key factor which affects the work state of the sludge discharge regulator is the opening and closing condition of the check valve. The opening of the check valve is controlled by the hydraulic pressure of the sludge channel. The analysis of the check valve is shown in Figure 4. The closing condition is represented by the formula (3)

$$
h_{\max }=\frac{p_{1 S_{w} L_{z}+G_{l} L_{z} \sin \theta-T_{z}}}{\rho_{w} g S_{n} L_{z}} .
$$

Where, $p_{l}$ is the flow pressure in the sludge channel, $S_{w}$ is the outside area of the check valve lid, $L_{Z}$ is the distance between the center of gravity of the check valve lid to the center of the shaft, $G_{l}$ is the weight of the check valve lid, $\theta$ is the angle between the line of which from the center of the lid shaft to the center of the lid gravity and the vertical plane, $S_{n}$ is the area that the water in the water chamber pushes on the check valve, $T_{z}$ is the resistance moment of the shaft. In this paper, $p_{I}=0.0033 \mathrm{~Pa}$, $S_{w}=0.001 \mathrm{~m}^{2}, L_{z}=0.02 \mathrm{~m}, G_{l}=18 \mathrm{~N}, \theta=15^{\circ}, T_{Z}=0.0005 \mathrm{Nm}, S_{n}=0.0008 \mathrm{~m}^{2}, h_{m i x}=0.591 \mathrm{~m}$,

The opening condition is represented by the formula (4)

$$
h_{\text {min }}=\frac{G_{l} L_{z} \sin \theta+T_{z}}{\rho_{w} g S_{n} L_{z}} \text {. }
$$

In this paper, $h_{\min }=0.597 \mathrm{~m}$.

The pressure value of $p_{l}$ affects the opening and closing condition of the check valve. The structure of the sludge channel affects the value of $p_{1}$.

\section{Design of the inlet port}

After the blockage releasing, the flow in the sludge channel will soon restore to the normal state. The water inlet port is normally in opening state, and it is always in the water. By the opening and closing condition of the sludge discharge regulator, it can be determined that when the volume of the inlet water reaches to $b V v$, the discharge regulator begins to decline until to the set position.

Assume that the returning response time is $T_{0}$, the section area of the inlet port can be calculated by the following formula

$$
A_{0}=\frac{\mathrm{b} V_{v}}{\varphi_{\mathrm{o}} \varepsilon_{\mathrm{o}} \sqrt{2 g H} T_{0}}
$$


Where, $A_{o}$ is the area of the inlet port section, $\varepsilon_{o}$ is contracted factor of the flow, $\varphi_{o}$ is velocity coefficient, $H$ is actual head. After the blockage released, in $T_{o}$ time the sludge discharge regulator begins to sink until to the normal status.

In the paper, $b V v=0.35 \mathrm{~m}^{3}, \varphi_{o}=0.82, \varepsilon_{o}=1, H=5.5 \mathrm{~m}, T_{0}=6 \mathrm{~s}, A_{0}=0.0082 \mathrm{~m}^{2}$.

\section{Design of the check valve orifice}

When the discharge port is blocked by large pieces of sludge, the fluid pressure in the sludge channel will be reduced. The water in the water chamber will push the check valve lid off and flows out rapidly. When the total gravity of the water in the water chamber and the regulator is smaller than the buoyancy, the regulator will go up. The discharge port will enlarge, then the large pieces of sludge will be discharged. The outlet area of the check valve is calculated by the follow formualr

$$
A_{a}=\frac{2\left(\varphi_{\mathrm{o}} \varepsilon_{\mathrm{o}} A_{o} \sqrt{2 g H} T_{0}+V_{w}\right)}{T_{0}{ }^{\prime} \mu \sqrt{2 g h}}
$$

Thus, $T_{0}{ }^{\prime}$ time later after the blockage released, the sludge discharge regulator begins to rise.

Where $A_{a}$ is the outlet area of the check valve, $V_{w}$ is the internal volume of the tank, $T_{0}{ }^{\prime}$ is returning response time of the sludge discharge regulator. In this paper, $T_{0}=6 \mathrm{~s}, T_{0}{ }^{\prime}=10 \mathrm{~s}, V_{w}=0.6927 \mathrm{~m}^{3}, \varphi_{o}=0.82$, $\varepsilon_{o}=1, \mu=0.82, H=5.5 \mathrm{~m}, h=0.579 \mathrm{~m}, A_{0}=0.0082 \mathrm{~m}^{2}, A_{a}=0.0805 \mathrm{~m}^{2}$.

\section{Conclusion}

The resistance moment $T_{r}$ is the basis of the structural design, it determines the size of the structure. The material density of the sludge discharge regulator must be bigger than water, the discharge regulator falls down by gravity.

The water level in the water chamber is higher than the set point, the water weight and the regulator is heavier than the buoyancy of the regulator, it will rotate downwards, and then the discharge port closes small.

The water level in the water chamber is lower than the set point, the water weight and the regulator is less than the buoyancy of the regoulator, it will rotate upwards, then the discharge port opens.

The grille rotates relatively to the comb, and the comb removes the dross which is filtered on the grille automatically, so as to make sure that the water in the water chamber is cleaning.

The discharge regulator can remove sludge under water, prevent the rainwater from polluting, then the rainwater can be good utilized for long-term. Therefore, in rainwater storage system, the sludge discharge regulator could be widely applied.

\section{Acknowledgements}

This work was financially supported by Natural 863 Project, Key technology for the whole life cycle design of earth machinery power train Foundation (10002430013).

\section{References}

[1] SHI Zuhui, HU Yanfei. Storage tank used in Combined Sewer System[J], Water Supply and Sewerage, 2008,07:43-45.

[2] XIAO Yan, XU Ji anchu. Design of flushing method for rainwater storage tank in Expo Pudong Park pumping station. Water Supply and Sewerage, 2009, 35(3):50 52.

[3] F Sieker. On-site storm water management as an alternative to conventional sewer systems: a new concept spreading in Germany. Wat. Sci Tech, 1998, 38(10): 65 71.

[4] ZHANG Chen, Study of overflow storage technology in combined sewerage system and its Application[J], Urban Roads Bridges \& Flood Control, 2006, 9(5):1 4.

[5] CHEN Jie. ZHAO Guozhi, WANG Bin, YOU Wenwei. Storage Tank and Its Application in the Suzhou River. Water supply and drainage and sewage treatment, 2004, 110(4):34 37 
[6] Wang Jian, ZHOU Yuwen, LIU Jia, SONG Ge. Briefing introduction about rainwater storage tank in the domestic application [J], Rainwater utilization, 2010, (3):6 9.

[7] CHEN Shuyu, LIU Xiang, ZHANG Shanfa, Design of storage tanks and pumping stations Combined Composite System

[8] ZHANG Fengyu. Fluid mechanics [M]. Beijing: China Water Power Press, 2013. 